\title{
Editorials
}

\section{The potential of placing a digital assistant in patients' homes}

\section{INTRODUCTION}

It is around 5 years since Amazon's 'Alexa' was first launched in 2014 and the novelty does not appear to be wearing off. It recently escalated into the UK's healthcare spotlight with the announcement ${ }^{1}$ of a new partnership between Alexa and the NHS website. The benefits promised by this partnership received a critical reception from several UK health professionals. While the focus has been on its new ability to search the NHS website to give health information to users, what has not caught current interest yet is its myriad of existing functions that can support people practically with chronic health problems.

This editorial relays findings of a pilot project in Stoke-on-Trent and across Staffordshire on behalf of the Sustainability and Transformation Partnership's (STP's) digital workstream las yet unpublished data), which has distributed 50 digital assistant kits (Alexa Echo Show plus WiFi if neededl to 50 patients with health or dependence needs. Initial findings are that with the aid of Alexa, patients report being better able to manage their health conditions and lead more independent lives. With the continuing national trends ${ }^{2}$ towards increased use of smart speakers in the home, it seems a good time to focus on how to use their existing functions for patients', and potentially for primary healthcare clinicians', mutual advantages.

\section{CURRENT CRITICISMS}

Several articles have been published by UK clinicians since the announcement by the Health Secretary ${ }^{1}$ and most are derisorily sceptical about the use and value of using Alexa to provide digital health information. One GP challenged Mr Hancock to '... put aside your fantasies of technological fixes and concentrate on realistic solutions to the urgent funding and workforce problems facing our NHS'. The same professional argued that without live clinical input, a set of benign symptoms searched for online

\section{what has not caught current interest yet is its}

[Amazon's Alexa] myriad of existing functions that can support people practically with chronic health problems.

may appear to be more serious than they actually are. This might then encourage more unnecessary assurance-seeking behaviours by patients, and contrary to the Health Secretary's promises, increase numbers of appointments. ${ }^{3}$ This is a legitimate problem, created in part by ease of access to all sorts of health information, some better than others. However, it is doubtful whether access to this same information by a different interface (for example, using voice instead of a keyboard) will exacerbate this

Another concern was that increased use of digital technology for health will potentially create a health divide between those who can afford it and those who cannot. ${ }^{4}$ While Chair of the RCGP. Professor StokesLampard raised this issue in response to the partnership announcement. ${ }^{5}$ This is a broader societal concern and not a criticism of the technology itself, speaking on the existing problem of wealth-driven, health inequalities. ${ }^{5}$ However, there are practical solutions to this. NHS England's 10-year Long-Term Plan (LTP) includes increased funding for 'social prescribing', so why not extend this to supporting those who come from poorer economic circumstances to access suitable health technology, where there is demonstrable benefit?

The final concern published was that there is a serious lack of ethical discussion about the adoption of health technologies prior to their promotion and use. ${ }^{7}$ Privacy of patient data is indeed a common concern and it is not clear what safeguards are in place to prevent hackers from stealing data,

\section{"The potential of voice-assistant technology is far greater than searching for health information and more, with real-world, practical applications}

or for third parties to literally be able to 'listen-in' on our private lives. For example, it emerged this year that small excerpts of audio are routinely monitored by live staff to 'improve services' without users' explicit consent or knowledge. ${ }^{8}$ Undoubtedly, if Amazon were to strengthen its relationship with the NHS further, then more robust, regulatory safeguards should be developed to protect patients' data.

\section{TRIAL OF ALEXA IN STOKE-ON-TRENT}

While these debates have been raging, no one has addressed how smart speakers are truly able to support those with chronic health conditions. In Stoke-on-Trent, the pilot project, supported by the STP with NHS resources, is leading the way in this regard, showing that devices like Alexa can be used for minor everyday activities to make a big difference to users management of their long-term conditions. Patients with dementia, multiple sclerosis, Behcet's disease, and generalised anxiety and depression are just a few examples of the illnesses that participants in the project contend with daily.

Increased independence: nearly all 30 Alexa recipients in the follow-up phone surveys have reported increased independence since using the Alexa Echo Show device for at least 2 months. For example, one patient with cognitive impairments used to require daily visits from her primary carer (her mum) to enable her to live in her own home and look after her son. Before the project she could not cook, take medication, remember appointments, nor pack her son's lunch for school. Three months later and she can do all of those activities with Alexa's prompts. Now her mum has to visit far less frequently, as she can use the companion app to set up reminders remotely for her daughter and ring her to see her on-screen, and her grandson knows how to call her if there are any 
problems too. This has had hugely positive effects for both patient and family carer, reducing anxieties for all and improving the whole family's quality of life.

Mental health: an unexpected outcome of the project was that, for those patients who live alone or are solitary for most of the day while their family carer works, having something to talk to that responds, tells them a fact or even a bad joke, was very comforting. Some patients described feeling embarrassed to admit this gain, so it should not be taken lightly, but it seems that the device can provide a welcome source of companionship for people. Loneliness has been recognised as a significant factor in depression 9.10 and while not suggesting that devices like Alexa can, or should, replace human interactions as a rule, if they can help to alleviate loneliness then this is surely a positive.

A potential resource for primary healthcare services: rather than focusing on the unproven benefits of the new partnership, what are the potential gains for primary health care from its more practical features? Take some of the biggest problems faced by the primary healthcare service in the UK: wasted prescriptions estimated at a cost of 300 million GBP per year ${ }^{11}$, missed appointments - estimated at over 15 million missed per year'2, or the management of ever more complex comorbidities in the ageing population:13 all of these problems could be tackled in part by smart use of smart speakers. The patient participants in the pilot project found using Alexa for medication reminders to be extremely helpful. For example, they were able to update Alexa as to what medications they take and when, and then be prompted to take them. Importantly, for those who had memory decline, it reminded them which medications they had already taken. Reminders were also used for hospital and GP appointments, of which the participants had many to remember. Additionally, the finding that the devices are very popular with the older generations makes the potential benefits greater and more credible, as they tend to use the health service most often; $>55$-year-olds account for $33 \%$ of all owners of smart speakers, whereas those aged 18-24 years make up just $10 \% .^{2}$ If accessibility and privacy concerns can be addressed, then using smart speakers should be a viable option to support primary health care and make the Health Secretary's so-called 'technological fantasy' a reality.

\section{CONCLUSION}

The potential of voice-assistant technology is far greater than searching for health information and more, with real-world, practical applications that are nonhealthcare specific but can be applied to patients' health and care needs. Pilot projects, like the one in Stoke-on-Trent, provide real-world examples of the ways in which Alexa could be used to support patients, with potential knock-on benefits for primary healthcare services too. Of course, attention must be paid to the current concerns levelled at the technology so that it better protects privacy and is accessible to all patients, yet pragmatic and forward-thinking solutions are required if we are to tackle the problems facing primary healthcare, and the use of smart speakers in patients' homes could play a part.

\section{Ruth Chambers,}

Clinical Lead for Technology Enabled Care Service (TECS) Programme, Staffordshire Sustainability and Transformation Partnership's Digital Workstream, Stoke-on-Trent.

\section{Paul Beaney,}

Medical Student and Project Evaluator of Patients Perceptions of the Use of Digital Assistants for TECS Programme, School of Medicine, Keele University, Stoke-on-Trent.

\section{Funding}

The Alexa equipment was funded by Northern Staffordshire Clinical Commissioning Groups and ongoing project delivery by NHS Estates and technology transformation funds, awarded to Staffordshire Sustainability and Transformation Partnership. The views expressed in this paper are those of the authors and not necessarily those of the NHS.

\section{Provenance}

Freely submitted; externally peer reviewed.

\section{Competing interests}

The authors have declared no competing interests.

\section{Acknowledgements}

The authors should like to thank Alex Rowley and Ben McManus of Wavemaker CIC; Paul Edden from Home Instead who helped to select recipients and install the Alexa Echo devices in their homes; and Ron Daley for programme management of the overarching digital inclusion project.

\section{Open access}

This article is Open Access: CC BY-NC 4.0 licence (http://creativecommons.org/licences/by-nc/4.0/).

DOI: https://doi.org/10.3399/bjgp20X707273

\section{ADDRESS FOR CORRESPONDENCE}

\section{Ruth Chambers}

Stoke-on-Trent CCG, One Smithfield, Leonard Coates Way, Hanley, Stoke-on-Trent ST1 4FA, UK

\section{Email: ruth chambersastoke.nhs.uk}

\section{REFERENCES}

1. Department of Health and Social Care. NHS health information available through Amazon's Alexa. 2019. https://uww.gov.uk/government/ news/nhs-health-information-availablethrough-amazon-s-alexa laccessed $22 \mathrm{Nov}$ 2019).

2. Feldman R. Smart speaker ownership doubles in six months. YouGov 2018; 19 Apr: https://yougov.co.uk/topics/politics/articlesreports/2018/04/19/smart-speaker-ownershipdoubles-six-months (accessed 22 Nov 2019).

3. Salisbury H. 'Alexa, can you do my job for me?'. BMJ 2019; 366: 14719.

4. Rimmer A. Sixty seconds on ... Dr Alexa. BMJ 2019; 366: 14684.

5. Stokes-Lampard H. Voice-assisted technology has potential, but we must not create a digital divide' between patients, says College. RCGP July 2019.

6. NHS England. Online version of the NHS Long Term Plan. https://www.longtermplan.nhs.uk/ online-version (accessed 22 Nov 2019).

7. McMillan C. Alexa, does this look infected? - We need to talk about safely regulating the digitisation of healthcare, now. BMJ Blogs 2019; 31 Jul: https://blogs.bmj.com/ medical-ethics/2019/07/31/alexa-does-thislook-infected-we-need-to-talk-about-safelyregulating-the-digitisation-of-healthcare-now laccessed 22 Nov 2019).

8. Cuthbertson A. Amazon admits employees listen to Alexa conversations. The Independent 2019; 11 Apr: https://uww.independent.co.uk/ life-style/gadgets-and-tech/news/amazonalexa-echo-listening-spy-security-a8865056. html laccessed 22 Nov 2019).

9. Erzen E, Çikrikci Ö. The effect of loneliness on depression: a meta-analysis. Int J Soc Psychiatry 2018; 64(5): 427-435.

10. Mind. Loneliness. 2019. https://www.mind. org.uk/information-support/tips-for-everydayliving/loneliness/\#.XVgZ9OhKg2w laccessed 22 Nov 2019).

11. NHS Business Services Authority. Pharmaceutical waste reduction in the NHS. 2015. https://www.england.nhs.uk/wp-content/ uploads/2015/06/pharmaceutical-wastereduction.pdf (accessed 22 Nov 2019).

12. NHS England. Missed GP appointments costing NHS millions. 2019. https://www.england.nhs. uk/2019/01/missed-gp-appointments-costingnhs-millions (accessed 22 Nov 2019).

13. British Medical Association. General practice in the UK - background briefing. 2017. https:// wuw.bma.org.uk/-/media/files/pdfs/news $\% 20$ views $\% 20$ analysis/press $\% 20$ briefings/generalpractice.pdf (accessed 22 Nov 2019). 